Japan, 14, 71 (1981).

16) Ohgaki, K., Y. Nakamura, H. Ariyasu and T. Katayama: $J$. Chem. Eng. Japan, 15, 85 (1982).

17) Ohgaki, K. and T. Katayama, J. Chem. Eng. Japan, 17, 65 (1984).

18) Reid, R. C., J. M. Prausnitz and T. K. Sherwood: "The Properties of Gases and Liquids," McGraw-Hill Co., New York (1977).
19) Trappeniers, N. J., T. Wassenaar and G. J. Wolkers: Physica's Grav., 82A, 305 (1975)

20) Tsonopoulos, C.: AIChE J., 20, 263 (1974).

21) Vukalovich, M. P. and Ya. F. Masalov: Thermal Engng., 13(5), 73 (1966).

22) Waxman, M., H. A. Davis and J. R. Hastings: Proc. 6th Symp. Thermophys. Props., Am. Soc. Mech. Engrs., New York, p. 245 (1973).

\title{
CONTRIBUTIONS OF ANNULUS AND DRAUGHT TUBE TO GAS-LIQUID MASS TRANSFER IN BUBBLE COLUMNS WITH DRAUGHT TUBE
}

\author{
Kozo KOIDE, KaZUYOSHI HORIBE, HisATSUGU KITAGUCHI AND NoRIAKI SUZUKI \\ Department of Chemical Engineering, Shizuoka University, Hamamatsu 432
}

Key Words: Mass Transfer, Bubble Column, Bubble Size, Gas Holdup, Interfacial Area, Chemical Reactor

\section{Introduction}

Experimental results on the gas holdup $\varepsilon$ and the volumetric liquid-phase mass transfer coefficient $k_{L} a$ in bubble columns with draught tube were reported in previous papers. ${ }^{3,4)}$ The purpose of this work is to clarify the contributions of the annulus and the draught tube to gas-liquid mass transfer in columns with draught tube under liquid batch operation.

For this purpose bubble sizes and gas holdups were measured in column A with draught tube and with gas dispersion into the annulus, and in column $\mathrm{D}$ with draught tube and with gas dispersion into the tube.

\section{Experimental}

The experimental apparatus was the same as shown in the previous papers. ${ }^{3,4}$ The dimensions of the columns are shown in Table 1. The liquids used in this work were demineralized water and $65 \mathrm{vol} \%$ glycerol aq. soln for column A, and tap water and $400 \mathrm{~mol}$. $\mathrm{m}^{-3}$ sodium sulfite aq. soln for column $\mathrm{D}$. The physical properties of these liquids were listed in the previous papers. ${ }^{3,4)}$ During each run, liquid was neither fed nor discharged, and tempeature was kept at $298.2 \pm 0.5 \mathrm{~K}$ for the liquids except sodium sulfite aq. soln, which was kept at $298.2 \pm 1 \mathrm{~K}$. The gas velocity $U_{G}$ of air was adjusted to $0.019-0.12 \mathrm{~m} \cdot \mathrm{s}^{-1}$.

Received January 5, 1984. Correspondence concerning this article should be addressed to K. Koide. K. Horibe is now with Shin Nihon Seitetsi Co., Ltd., Himeji 671-11. N. Suzuki is now with Hamanatsu Technical High School, Hamamatsu 433.
The gas holdups $\varepsilon_{a}$ in the annulus and $\varepsilon_{i}$ in the draught tube were obtained from the static pressure distributions observed in the annulus and in the draught tube. The average gas holdup $\bar{\varepsilon}$ was evaluated by using experimental data of clear liquid height and aerated liquid height.

For column A, photographs of bubbles in the annulus and the draught tube were taken in three regions at different levels from the base plate. More than 100 bubbles were sampled for each region, and the volume-surface mean diameters $\left(d_{v s}\right)_{a}$ and $\left(d_{v s}\right)_{i}$ were evaluated. For column D $\left(d_{v s}\right)_{a}$ was obtained by the same photographic method as that for column A. Since bubbles in the draught tube could not be photographed due to an obstruction of bubbles in the annulus, $\left(d_{v s}\right)_{i}$ was obtained by the electric resistivity

Table 1. Experimental apparatus

\begin{tabular}{ccccccc}
\hline $\begin{array}{c}D_{o} \\
{[\mathrm{~m}]}\end{array}$ & $\begin{array}{c}D_{i}^{*} \\
{[\mathrm{~m}]}\end{array}$ & $\begin{array}{c}H \\
{[\mathrm{~m}]}\end{array}$ & $\begin{array}{c}H_{L} \\
{[\mathrm{~m}]}\end{array}$ & $\begin{array}{c}L / D_{i} \\
{[-]}\end{array}$ & $\begin{array}{c}\delta \\
{[\mathrm{mm}]}\end{array}$ & $\begin{array}{c}N \\
{[-]}\end{array}$ \\
\hline $\begin{array}{c}\text { Column A } \\
0.140\end{array}$ & 0.082 & 1.40 & 1.54 & $1 / 2$ & $2,3,4$ & $12^{* *}$ \\
$\begin{array}{c}\text { Column D } \\
0.140\end{array}$ & 0.066 & 1.40 & 1.54 & $1 / 2$ & 3 & 1 \\
0.140 & 0.082 & 0.70 & 0.84 & $1 / 2$ & 3 & 1 \\
0.140 & 0.082 & 1.40 & 1.54 & $1 / 2$ & 3 & 1 \\
0.140 & 0.104 & 1.40 & 1.54 & $1 / 2$ & 3 & 1 \\
\hline
\end{tabular}

* Wall thickness of draught tube is $3 \mathrm{~mm}$.

** The orientation of multi-nozzles is shown elsewhere. ${ }^{3\}}$ 
method $^{6)}$ using twin electric resistivity probes, the tips of which were located on a vertical line with a distance of $2.5 \mathrm{~mm}$ between them. Local gas holdup, bubble velocity, bubble frequency and bubble size were measured at five radial positions, the vertical levels of which were $(L+0.5 H) \mathrm{m}$ from the base plate, and $\left(d_{v s}\right)_{i}$ was obtained by the method shown elsewhere. ${ }^{6)}$ To examine the validity of evaluating $\left(d_{v s}\right)_{a}$ and $\left(d_{v s}\right)_{i}$ by different methods for the column $\mathrm{D}$, the specific interfacial area was measured by the chemical absorption method ${ }^{1)}$ of utilizing oxygen absorption by $400 \mathrm{~mol} \cdot \mathrm{m}^{-3}$ sodium sulfite aq. soln with $10^{-3} \mathrm{~mol}$. $\mathrm{m}^{-3} \mathrm{CoSO}_{4}$ as catalyst, and compared to $\bar{a}$ evaluated from Eqs. (1) and (2).

$$
\begin{gathered}
a_{j}=6 \varepsilon_{j} /\left(d_{v s}\right)_{j}, \quad(j=a, i) \\
\bar{a}=\left\{a_{a} \phi_{a}+a_{i}\left(1-\phi_{a}\right)\right\}\left(\bar{\varepsilon} / \varepsilon_{\mathrm{av}}\right)
\end{gathered}
$$

where $\phi_{a}=V_{a} /\left(V_{a}+V_{i}\right)$ and $\left(\bar{\varepsilon} / \varepsilon_{\mathrm{av}}\right)$ is a correction term to evaluate $\bar{a}$ based on the total volume of the aerated liquid.

\section{Results and Discussion}

Figures 1 and 2 show that $\varepsilon_{a}>\varepsilon_{i}$ and $\left(d_{v s}\right)_{a}>\left(d_{v s}\right)_{i}$ for column $\mathrm{A}$ and vice versa for column $\mathrm{D}$, i.e., $\varepsilon$ and $d_{v s}$ for gas-liquid upward flow are larger than those for gas-liquid downward flow. Bubble sizes in the downward flow were almost constant at different vertical positions, but local gas holdup increased with increasing height from the base plate.

Figure 3 shows that the specific interfacial area for the downward flow is larger than that for the upward flow. Figure 4 shows that $\bar{a}$ for $\mathrm{Na}_{2} \mathrm{SO}_{3}$ aq. soln agrees $a_{c}$ obtained by the chemical method in the range of $U_{G}>0.04 \mathrm{~m} \cdot \mathrm{s}^{-1}$, but shows larger value than that for $a_{c}$ in the range of $U_{G}<0.03 \mathrm{~m} \cdot \mathrm{s}^{-1}$. The reason for the latter phenomenon might be that in the range of $U_{G}<0.03 \mathrm{~m} \cdot \mathrm{s}^{-1}$ most bubbles are nearly stationary in the downward flow, and so the oxygen concentration of air bubbles in the downward flow decreases with time to reduce the value of $a_{c}$ obtained by assuming the constant oxygen concentration of air bubbles. Figure 4 also shows that $a_{c}$ values observed by Hirner et $a l^{2)}$ in a column of $D_{o}=0.29 \mathrm{~m}$ roughly agree with $a_{c}$ values observed in this work. As shown in Fig. $4, \bar{a}$ in column $\mathrm{A}$ of the air-water system increases with decreasing nozzle diameter. This might be the reason for the previous result ${ }^{3}$ that $k_{L} a$ for the air-water system increases with decreasing nozzle diameter. $\bar{a}$ in column $\mathrm{D}$ of the air-water system decreases with increasing $\left(D_{i} / D_{o}\right)$, since the crosssectional area of the annulus whose value for $a_{a}$ is larger than that for $a_{i}$ decreases. This might be the reason for the previous result ${ }^{4)}$ that $k_{L} a$ decreases with increasing $\left(D_{i} / D_{o}\right)$.

The mass transfer coefficients $k_{L a}$ and $k_{L i}$, re-
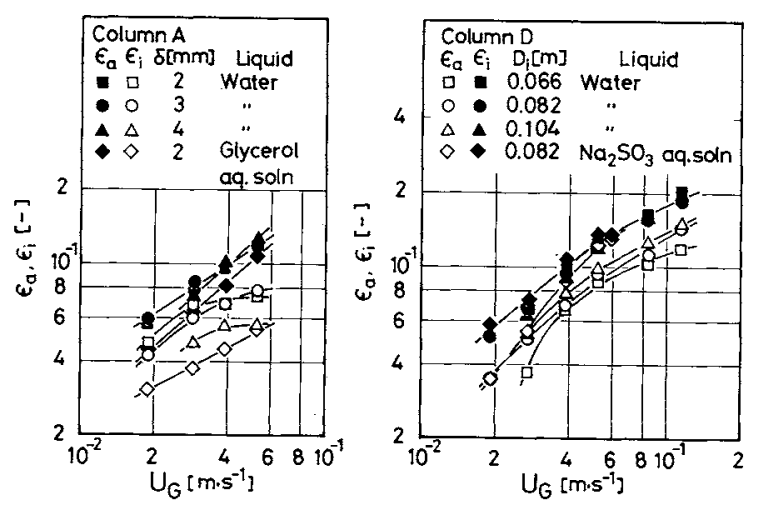

Fig. 1. Gas holdups in annulus and draught tube.
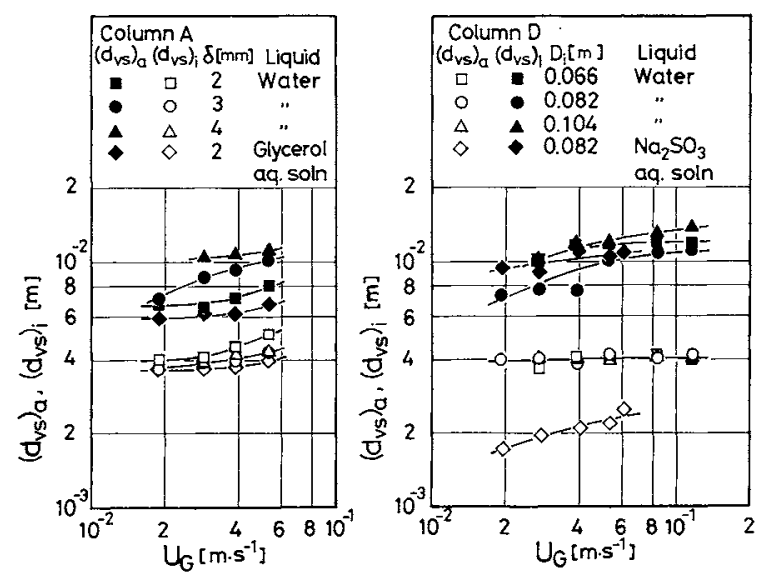

Fig. 2. Volume-surface mean diameters of bubbles in annulus and draught tube.
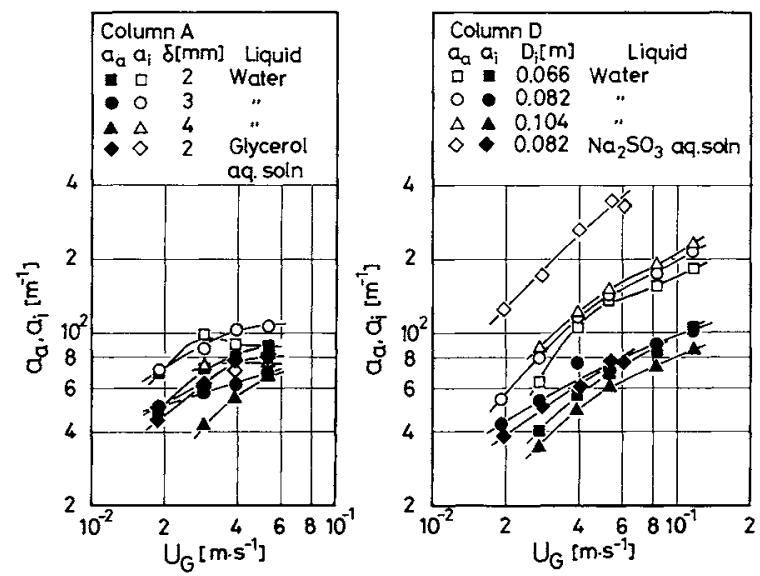

Fig. 3. Specific gas-liquid interfacial areas in annulus and draught tube.

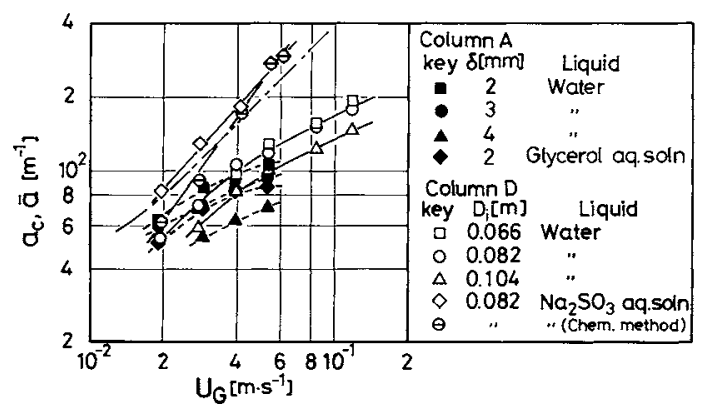

Fig. 4. Specific gas-liquid interfacial area of column. (Dotdashed line: $\mathrm{Na}_{2} \mathrm{SO}_{3}$ aq. soln, Hirner et al. ${ }^{2)}$ ). 
spectively, for bubbles in the annulus and the draught tube were estimated by the equation of Shirotsuka $e t$ $\left.a l .{ }^{5}\right)$ for $k_{L}$ of single bubbles, and $\left(k_{L} a\right)_{\text {est }}$ were evaluated by Eq. (3).

$$
\left(k_{L} a\right)_{\mathrm{est}}=\left\{k_{L a} a_{a} \phi_{a}+k_{L i} a_{i}\left(1-\phi_{a}\right)\right\}\left(\bar{\varepsilon} / \varepsilon_{\mathrm{av}}\right)
$$

Figure 5 shows that $\left(k_{L} a\right)_{\text {est }}$ agrees roughly with $\left(k_{L} a\right)_{\text {obs }}$ reported in the previous papers, ${ }^{3,4)}$ although at low gas velocity $\left(k_{L} a\right)_{\text {obs }}$ is smaller than $\left(k_{L} a\right)_{\text {est }}$ for the same reasion as that for the phenomenon of $\bar{a}>a_{c}$.

The relative contribution $\psi_{a}$ of the annulus to gasliquid mass transfer in the column is defined by Eq. (4).

$$
\psi_{a}=k_{L a} a_{a} \phi_{a} /\left\{k_{L a} a_{a} \phi_{a}+k_{L i} a_{i}\left(1-\phi_{a}\right)\right\}
$$

Figure 6 shows $\psi_{a} \geqq 0.7$ even for $\phi_{a}=0.409$ in column D. In column A of the air-water system, $\psi_{a}<0.5$ for $\phi_{a}=0.638$ when nozzles of $\delta=3$ or $4 \mathrm{~mm}$ were used, but when nozzles of $\delta=2 \mathrm{~mm}$ were used for air-water and air-glycerol aq. soln systems, $\psi_{a} \simeq \phi_{a}$. These observations indicate that the contributions of the downward flow sections (the draught tube of column $A$ and the annulus of column D) to gas-liquid mass transfer in the columns with draught tube are relatively large in the air-water system, but when bubble sizes and their terminal velocity become small, the contributions of the downward flow section and the upward flow section to gas-liquid mass transfer in the column become proportional to each volume fraction, i.e., $\psi_{a} \simeq \phi_{a}$.

\section{Acknowledgment}

The authors are highly grateful to Asahi Garasu Kogyogizyutsu Shoreikai for generous financial support of this research work.

\section{Nomenclature}

$=$ special gas-liquid interfacial area based on aerated liquid volume

$D_{i} \quad=$ inner diameter of draught tube

$D_{0} \quad=$ inner diameter of column

$d_{v s} \quad=$ volume-surface mean diameter of bubbles

$H \quad=$ length of draught tube

$H_{L} \quad=$ clear liquid height

$k_{L} \quad=$ liquid-phase mass transfer coefficient $\quad\left[\mathrm{m} \cdot \mathrm{s}^{-1}\right]$

$k_{L} a=$ volumetric liquid-phase mass transfer coefficient based on aerated liquid volume

$L=$ distance between lower end of draught tube and base plate of column

$N \quad=$ number of holes or nozzles

$U_{G} \quad=$ gas velocity based on cross section of column

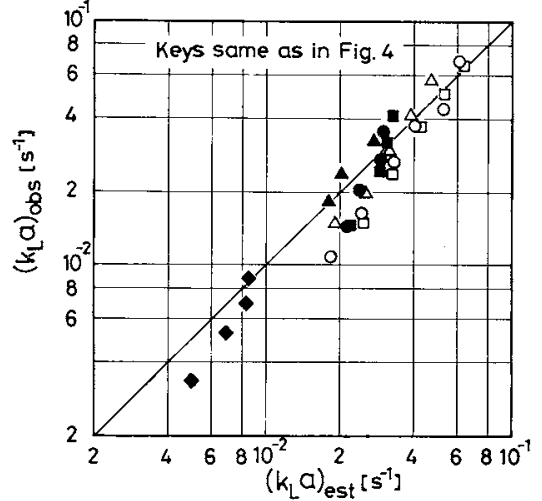

Fig. 5. Comparison of $k_{L} a$ estimated by Eq. (3) with values observed in previous works. ${ }^{3,4\}}$

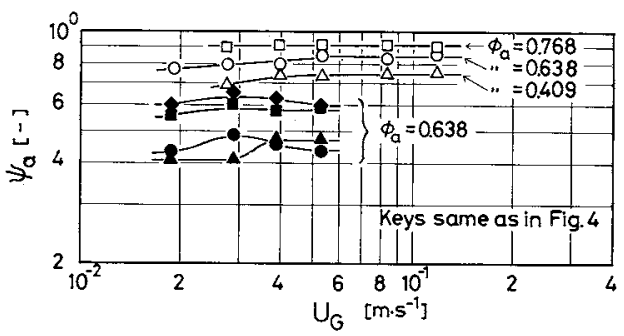

Fig. 6. Contribution of annulus to gas-liquid mass transfer in column.

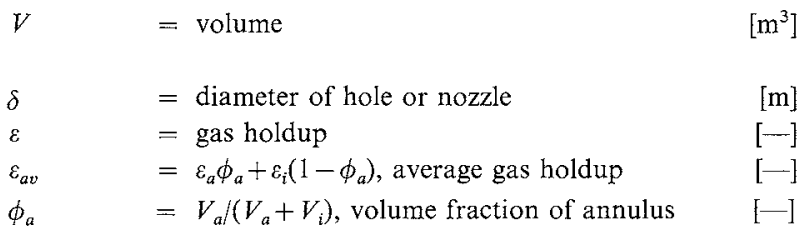

〈Subscript〉

$\begin{array}{ll}a & =\text { annulus } \\ c & =\text { chemical method } \\ \text { est } & =\text { estimated value } \\ i & =\text { draught tube } \\ \text { obs } & =\text { observed value }\end{array}$

\section{Literature Cited}

1) Charpentier, J. C.: Advan. Chem. Eng., 11, 1 (1981).

2) Hirner, W. and H. Blenke: Verfahrenstechnik, 11, 297 (1977).

3) Koide, K., H. Sato and S. Iwamoto: J. Chem. Eng. Japan, 16, 407 (1983).

4) Koide, K., K. Kurematsu, S. Iwamoto, Y. Iwata and K. Horibe: J. Chem. Eng. Japan, 16, 413 (1983).

5) Shirotsuka, T. and A. Hirata: Kagaku Kōgaku, 35, 78 (1971).
6) Ueyama, K., S. Morooka, K. Koide, H. Kaji and T. Miyauchi: Ind. Eng. Chem., Process Des. Develop., 19, 592 (1980). 